\title{
AC 2010-1475: FOSTERING INTERNATIONAL FACULTY COLLABORATION THROUGH STUDENT EXCHANGE PROGRAMS WITH A RESEARCH COMPONENT
}

\section{Ilka Balk, University of Kentucky}

Ilka Balk, a native of Germany, joined the University of Kentucky's College of Engineering in January of 2006, in order to start and establish a German and Engineering Program. In the fall of 2007, Ilka took on the added responsibility of Director of Cooperative Education. Ilka has lived and worked in Germany and the United States, and has a Masters in Political Science with minors in History and Communications from the University of Goettingen, Germany.

\section{John Balk, University of Kentucky}

John Balk is an assistant professor of Materials Engineering at the University of Kentucky. Before coming to UK, Dr. Balk was a staff scientist at the Max Planck Institute for Metals Research in Stuttgart, Germany, where he also completed his post-doctoral work. Dr. Balk received his $\mathrm{PhD}$ and MS degrees in Materials Science \& Engineering from The Johns Hopkins University. He received his BS degree from the University of California, Berkeley, where he double-majored in Mechanical Engineering and Materials Science \& Engineering. He has authored over 40 journal articles and conference proceedings, and is faculty advisor to the Material Advantage student chapter at UK. 


\title{
Fostering International Faculty Collaboration \\ through Student Exchange Programs with a Research Component
}

\begin{abstract}
In 2006, the College of Engineering at the University of Kentucky began developing an Engineering and German Studies Program, which included both study and work abroad, as well as intensive language immersion options for the College's students.

Leveraging a new faculty member's existing connection to German faculty members at the Karlsruhe Institute of Technology (KIT), an exchange program was conceived and then began in the spring of 2007. The program is designed so that, each year, the US institution's students arrive in Karlsruhe between January and March, and start with a research project that has been formulated by faculty at both institutions. Whenever possible, the US student is paired with a German student who will participate in the reciprocal phase of the exchange program. When the semester begins in Karlsruhe in April, students transition to coursework and either finish their research or decrease their laboratory workload.

The engineering students from Karlsruhe, Germany, come to the University of Kentucky in August to take regular classes in the fall semester. Karlsruhe's engineering students, who are required to complete a 500-hour research project for their degree, perform some of this research in the fall semester, while also taking classes, and switch to full-time research after final exams. The research completed by the exchange students is a collaborative project between the professors in the United States and Karlsruhe. Because the duration of each student's time abroad is roughly one and a half semesters, consisting of one academic semester and part of the semester break(s), German and American students overlap at both universities. This interaction occurs both in the classroom and in the laboratory, and facilitates continuity in the research projects.
\end{abstract}

The students and faculty have enjoyed early success with this arrangement. Two of the collaborative research projects have led to publications in a respected materials science journal. The exchange has also fostered further collaboration between professors on both sides of the Atlantic, resulting in invited seminars and joint proposals. Currently in its third year, the research exchange has grown to six "pairs" of faculty, who are now working together. We will expand this program to include additional faculty as we increase the numbers of student participants.

\section{The Exchange Program with the Karlsruhe Institute of Technology (formerly the University of Karlsruhe)}


When the College of Engineering at the University of Kentucky decided to offer more international experiences for its students in 2006, its motivation was mostly to help better prepare students for a global business and engineering environment. The College leveraged existing collaborations with faculty members in order to create an exchange program.

After about a year of planning and drafting an exchange agreement, which involved not only the respective schools of engineering and a few of its faculty members, but also the schools' Offices of International Affairs, the University of Kentucky sent its first cohort of three students to the University of Karlsruhe/Karlsruhe Institute of Technology (KIT) in January of 2007.

As part of the program, US students begin their exchange with KIT in January or February and continue until the end of the Karlsruhe summer semester (in late July), thereby using only one semester of their time at the University of Kentucky. Shortly after their return home, US Students start their fall semester at the end of August. The semester in Germany does not start until April, so students have time to become acquainted with the city, take language classes, and start a full-time research project for which they will receive credit from their home institution. The Karlsruhe Institute of Technology sends its students to the University of Kentucky in August, which is shortly after the beginning of their 11-week summer break, and they stay through February or March of the following year, before the beginning of the German summer semester. The German students take fall semester classes at the University of Kentucky and begin their research projects during the fall semester. After the semester ends, they focus exclusively on research, which is a required, 500-hour project and results in a thesis. A pair of faculty, one from each institution, formulates and supervises the project and its progress, but the home institution awards credit towards graduation for the project.

The advantage to our undergraduates is that they are paired with German students on a research project, so that both gain an appreciation and understanding of the other's background, knowledge, and overall educational experience. Based on their own experience in exchange programs, authors know this is an excellent way to gain international exposure and learn about other cultures. It is also increasingly important to have such an experience, as international collaborations are the rule, rather than the exception, for successful scientists ${ }^{1}$. Unfortunately, engineers make up less than $3 \%$ of students studying abroad, even though $6 \%$ of Bachelor's degrees are awarded to engineering students ${ }^{1,2}$.

In its first three years, the exchange program has brought six US students to Karlsruhe, and seven German students to the University of Kentucky. Moreover, it has become apparent that students are not the only beneficiaries of this and other student exchanges. Faculty members on both sides of the exchange program have fostered their relationships, which have positioned the exchange on a stronger foundation. 
By having students work on a co-advised project almost year-round, faculty pairs work on projects of shared interest on a continual basis. Furthermore, the next student can pick up the project and resume work on it, if further results are desired. Three years into the program, the 13 students from both countries have worked with six different faculty pairs.

One faculty pair has worked together in each of these past three years. The two Materials Engineers have been able to work collaboratively for all three years. The co-operation exists, through the continuous exchange of research and students, on a permanent basis. It has also been helpful to have this pair of "core" faculty continuously involved, since they share a thorough understanding of the mechanics of this program. They have been able to advise students and even university administrators about the logistics and the required paperwork on each side, such as visa issues, housing, and course enrollments.

\section{Funding and Financial Aspects of the Exchange}

Each university has been able to support its own students and defray some of the expenses in this exchange, such as airfare. Students from the University of Kentucky have the option to apply for university-wide study abroad scholarships. Furthermore, the College of Engineering has received an annual grant from an alumnus of this university, some of which was made available to students as scholarships. The College is currently working to secure more permanent funding, possibly through an endowment.

The College has one staff member who co-ordinates this program as part of her work as co-op director. Coordinating the exchange program is about 10 percent of her effort, which is funded by the college.

On the German side, KIT identifies its students early, and is able to hire them as "Hilfswissenschaftler" (research assistants) in the months before going abroad. The stipend they receive for this research work helps pay for the plane ticket or other expenses.

The research that is conducted through this exchange and via the faculty co-operation, has another added benefit. It gives the parties involved access to funding from two countries' sources. In the case of these research projects, funding has been requested from the National Science Foundation (NSF) and the Deutsche Forschungs Gemeinschaft (DFG), the German equivalent to $\mathrm{NSF}^{3,4}$. There are multiple other funding opportunities for transatlantic cooperation available to universities, which research exchange programs could possibly tap into. The University of Kentucky will continue to apply for funding to increase co-operation and future research. 
The research has also resulted in one published paper, on which the exchange student was first author. The paper was published in Scripta Materialia, and had co-authors from both institutions ${ }^{5}$. An additional manuscript is under preparation for submission to Scripta Materialia.

\section{Course Equivalencies and Academic Content}

The students who have participated in this exchange have majored in either Materials Engineering or Mechanical Engineering. The Materials Engineering students tend to be in their second semester of their sophomore year, and the Mechanical Engineering students are usually in the second semester of their junior year. This is due to the classes that are offered by KIT in English. In order to obtain as many credit hours as possible during the exchange, Materials Engineering students take Materials Science II and Circuits at KIT, both of which are offered in English. Mechanical Engineering students take Thermo II, which is offered in English, and Circuits during their semester abroad. Additionally, they take a technical elective and can choose from a number of other classes, which can possibly also be used as technical electives.

While it is rather early for a sophomore to spend a semester abroad, the course offerings in English effectively restrict us to do it this way. Most of our students have not had the chance to take German in high school, so their language skills are usually not good enough to take technical courses taught in German. However, our experience with sending the Materials Engineering students early has so far been positive. Most students have done very well with their research, despite the fact that they had not completed upper-level coursework in Materials Engineering. It has also helped some of them identify an emphasis in their field of study, such as Metals rather than Ceramics, for example. Providing Materials Engineering students with an early experience abroad has also given them the chance to follow up on their experience more profoundly. One student has continued his German language classes after the experience, and is scheduled to graduate in May with a double major in German as well as Materials Engineering. He is currently applying for two graduate programs (taught entirely in German) in Germany, which would begin in Fall 2010.

It has been rather difficult to establish official course equivalencies with KIT, mostly because of our institution's cautiousness to accept credits from a non-ABET-accredited institution. Once students complete their coursework there, they can bring all documentation back to the US, and our departments look at the course and identify equivalencies. At this point, the three courses, Circuits, Thermodynamics II and Materials Science II, have been accepted as equivalencies by the University of Kentucky. Other courses will be added to this as students take new classes overseas.

The US Students have also had trouble adjusting to the different teaching methods in Germany. There, grades in most courses are based solely on the final exam, and do not include homework, 
attendance or quizzes (in contrast to universities in the United States). This approach to grading demands more discipline of our students to keep up with the coursework, since there is no one to provide regular feedback or periodically check on their progress. In response to this, we have tried to prepare our students through orientations and by making experience reports from previous years available to new candidates.

On the German side, there have also been very few problems with the exchange. Students usually participate in their third year of study. The students from Germany tend to be academically well prepared to take courses in the United States. The German students can often get their engineering courses from the United States accepted at KIT, either as a free or technical elective. They often also add a course that is not strictly required, but which they might have an

interest in. Studying at a US institution that offers many extracurricular opportunities, including college athletic events, has been an enriching experience for them. This is a significant difference to typical German universities, which do not integrate extracurricular activities into their university experience.

The research collaborations have worked so well that in 2008, KIT and the University of Kentucky began to send KIT students to the University of Kentucky exclusively for research, in addition to the exchange students. The research students come to the United States for six to seven months in order to conduct research for their Diploma thesis (roughly the equivalent of a Master's thesis), which they write immediately following their work in the US. In both years so far, faculty have expressed an interest in at least one student coming back to the University of Kentucky for PhD work. It is still too early to know whether the students will opt to do this, since neither student has finished the degree yet.

\section{Conclusion}

The exchange program has worked very well because it has combined research and coursework. This combination has helped alleviate some of the "timing" issues due to the offset academic calendars at both institutions. The program's schedule has provided both universities and the faculty involved with an opportunity to conduct ongoing research and an incentive to continue research projects across the Atlantic. There are some logistical difficulties, but overall, the exchange has been a relatively low-cost way for exchange of students and ideas across the Atlantic, and the benefits for students and faculty have far outweighed any cost involved. The University of Kentucky has also used the program to attract high-quality student recruits, especially with a background in the German language, to the College of Engineering, and we will continue to advertise this and other international opportunities to future students and their parents. 


\section{Bibliography}

1. Brenn-White, M., The Science of Studying Abroad: Why Scientists and Engineers Don't Go Abroad, Why They Should, and How to Make it Happen, IIE Networker (Institute of International Education) p. 48 (Fall 2005).

2. Open Doors: Report on International Educational Exchange, (Institute of International Education) 2000

3. National Science Foundation, Materials World Network funding request, November 2007

4. National Science Foundation, Engineering Directorate, Proposal submitted February 2010

5. Lohmiller et al., Mechanical Spectroscopy of Nanocrystalline Nickel Near Room Temperature, Scripta Materialia 59 (2008), p. 467-470 